\title{
EFEKTIFITAS PENUSUKAN TITIK ZUSANLI (ST 36) DAN TAICHONG (LR 3) PADA KASUS MELASMA IBU GURU SMPN III COLOMADU, KARANGANYAR
}

\author{
Joko Tri Haryanto, Abhiseka Kristiyana \\ Kementerian Kesehatan Politeknik Kesehatan Surakarta Jurusan Akupunktur
}

\begin{abstract}
Transfixion Point Zusanli (St 36) and Taichong (Lr 3), Melasma. The effectiveness of Transfixion Point Zusanli (St 36) and Taichong (Lr 3) in the case of Junior High School Teacher Mother land of Melasma III Colomadu, Karanganyar. Melasma is a skin hyperpigmentation disorders face in the form of macula/patch symmetrical hyperpigmentation in the region of the forehead, around the nose, around the mouth, around the eyes, cheeks, and Chin with yellow-brownish or dark brownish to blackish, without subjective complaints of patients. Factors of the incidence of this disorder is ultraviolet radiation, hormone MSH, sex hormone imbalance and the contraceptive pill. Stabbing point Zusanli (ST 36) and Thaichong (Lr 3) can be perperan in the body's hormonal balance. The purpose of this study to the effectiveness of Zusanli and Taichong point stabbing on the case of melasma. the design research of using "One Group Pretest-Postest Design. Technique of data analysis with the Wilcoxon test and using a Purposive sampling technique of Sampling a number of 26 respondents. Wilcoxon Test on against darkness level melasma before and after stabbing point Zusanli and Taichong obtained that the value of significance $p=0.05$, $0.014<$ is no difference color darkness level melasma before and after stabbing Zusanli and Taichong point, in other words the use of points Zusanli and Taichong effective for lowering the level of the dark color of the melasma.
\end{abstract}

Keywords : Transfixion Point Zusanli (St 36) and Taichong (Lr 3), Melasma

Abstrak : Penusukan Titik Zusanli (St 36) Dan Taichong (Lr 3), Melasma. Efektifitas Penusukan Titik Zusanli (St 36) Dan Taichong (Lr 3) Pada Kasus Melasma Ibu Guru SMP Negeri III Colomadu, Karanganyar. Melasma adalah kelainan hiperpigmentasi kulit wajah berupa makula/ patch hiperpigmentasi yang simetris di daerah dahi, sekitar hidung, sekitar mulut, sekitar mata, pipi, dan dagu dengan warna kuning-kecoklatan atau kecoklatan gelap hingga kehitaman, tanpa disertai adanya keluhan subyektif dari pasien. Faktor timbulnya kelainan ini adalah radiasi sinar ultraviolet, Hormon MSH, Ketidakseimbangan hormon kelamin dan pil kontrasepsi. Penusukan titik Zusanli (ST 36) dan Thaichong ( $\operatorname{Lr} 3$ ) dapat perperan dalan keseimbangan hormon tubuh. Tujuan penelitian ini untuk efektifitas penusukan titik Zusanli dan Taichong pada kasus melasma. rancangan penelitian menggunakan "One Group Pretest-Postest Design. Teknik analisa data dengan uji Wilcoxon dan menggunakan teknik sampling Purposive Sampling sejumlah 26 responden. Pada Uji Wilcoxon terhadap tingkat kegelapan melasma sebelum dan sesudah penusukan titik Zusanli dan Taichong didapatkan bahwa nilai signifikansi $\mathrm{p}=0,014<0,05$, ada perbedaan tingkat kegelapan warna melasma sebelum dan sesudah penusukan titik 
Zusanli dan Taichong, dengan kata lain penggunaan titik Zusanli dan Taichong efektif untuk menurunkan tingkat kegelapan warna melasma.

Kata Kunci : Penusukan Titik Zusanli (St 36) Dan Taichong (Lr 3), Melasma

\section{PENDAHULUAN}

Melasma merupakan salah satu masalah kulit yang banyak dijumpai, karena menimbulkan gangguan pada kulit wajah sekaligus menyebabkan penurunan kepercayaan diri penderitanya, berupa makula hiperpigmentasi tidak merata yang umumnya simetris. Etiologi melasma sampai saat ini belum diketahui pasti, tetapi ada beberapa faktor risiko yang dianggap berperan pada patogenesisnya antara lain : sinar matahari, hormon, obatobatan, genetik, kosmetik, riwayat penyakit lain, usia, dan pekerjaan. (Dwi P, 2012)

Melasma adalah kelainan hiperpigmentasi kulit wajah berupa makula/ patch hiperpigmentasi yang simetris di daerah dahi, sekitar hidung, sekitar mulut, sekitar mata, pipi, dan dagu dengan warna kuning-kecoklatan atau kecoklatan gelap hingga kehitaman, tanpa disertai adanya keluhan subyektif dari pasien. Faktor timbulnya kelainan ini adalah radiasi sinar ultraviolet, Hormon MSH, Ketidakseimbangan hormon kelamin dan pil kontrasepsi. (Brown G.R., Burns T. 2005)

Berdasarkan penelitian Tia Febrianti, Aryani Sudharmono, IGAK Rata, Irma Bernadette di Departemen Ilmu Kesehatan Kulit dan Kelamin FK Universitas Indonesia/RS. Dr. Cipto Mangunkusumo, Jakarta tahun 2004 menunjukkan hasil bahwa epidemiologi melasma $97,93 \%$ wanita dan $2,07 \%$ pria. Terutama tampak pada wanita usia subur dengan riwayat langsung terkena pajanan sinar matahari. Insidens terbanyak menurut penelitian Rikyanto yang berkonsultasi ke Poli Kulit RSUD Kota Yogyakarta selama 3 tahun (Juni 2001Juli 2003), kelompok umur kasus melasma terbanyak pada kelompok usia 31-40 tahun (42,4\%), dengan frekuensi kunjungan terbanyak adalah $1 \mathrm{x}$ kunjungan dan pasien memiliki pekerjaaan yang umumnya adalah pegawai negeri sipil $(57,3 \%)$.

\section{METODE PENELITIAN}

Jenis penelitian ini adalah pre eksperiment dengan rancangan penelitian menggunakan "One Group PretestPostest Design. Sampel adalah Guru SMP N 3 Colomadu, Karangnyar berjenis kelamin Wanita yang diambil secara Purposive Sampling. Kriteria inklusi adalah wanita usia 30 sampai dengan 60 tahun, dan bersedia menjadi responden. Kriteria Ekslusi adalah klien yang tidak mematuhi jadwal rutin 1 minggu 2 kali, klien yang tidak melakukan terapi sebanyak 10 kali, klien yang menggunakan terapi selain akupunktur. Instrument penelitian menggunakan blangko observasi pasien, alal terapi menggunakan bahan habis pakai, jarum akupubnktur Huanqiu berukuran 1 cun, alat elektro stimulator KWD yin di, kamera digital Canon PS 1100 IS 12.1 mega pixels. Analisa unvariat dan analisa bivariat menggunakan Uji Wicoxon.

\section{HASIL PENELITIAN}

Hasil penelitian Efektifitas Penusukan Titik Zusanli (St 36) Dan Taichong (Lr 3) Pada Kasus Melasma Ibu 
Guru SMPN 3 Colomadu, Karanganyar secara diskriptif disajikan dalam tabel distribusi frekuensi dibawah ini :

Karakteristik Responden

Data karakteristik responden penelitian yaitu karakteristik responden berdasarkan usia, data karakteristik tersebut disajikan dalam tabel distribusi frekuensi sebagai berikut ;

a. Umur

\section{Tabel 1}

Distribusi Frekuensi Karakteristik

Responden Penelitian Berdasarkan Usia

\begin{tabular}{lllll}
\hline No. & Usia & & Frekuensi & Persentase \\
\hline 1. & $\begin{array}{l}30- \\
\text { tahun }\end{array}$ & 85 & $30.8 \%$ \\
2. & $\begin{array}{l}45-60 \\
\text { tahun }\end{array}$ & 18 & $69.2 \%$ \\
\hline Jumlah & & & $100 \%$ \\
\hline
\end{tabular}

Dari tabel 4 didapatkan sebanyak 8 responden berusia antara 30 - 45 tahun dengan persentase $30.8 \%$ dan responden penelitian berusia 45 - 60 tahun sebanyak 18 orang dengan persentase $69 \%$.

b. Tingkat kegelapan warna melasma sebelum terapi

Tabel 2

Gambaran Kegelapan Melasma Sebelum Terapi Menggunakan Titik Zusanli Dan Taichong.

\begin{tabular}{lll}
\hline Kategori & Jumlah & Persentase \\
\hline Ringan & 4 & $15.4 \%$ \\
Sedang & 17 & $65.4 \%$ \\
Berat & 5 & $19.2 \%$ \\
\hline Total & 26 & $100.0 \%$ \\
\hline
\end{tabular}

Dari tabel 2 diketahui responden mengkategorikan tingkat kegelapan melasma sebelum dilakukan penusukan pada titik Zusanli dan Taichong. Kategori ringan berjumlah 4 responden dengan persentase $15.4 \%$, kategori sedang berjumlah 17 orang dengan persentase $65.4 \%$, dan kategori berat berjumlah 5 orang dengan persentase $19.2 \%$

$$
\begin{aligned}
& \text { c. Tingkat kegelapan warna } \\
& \text { melasma sesudah terapi }
\end{aligned}
$$

Tabel 3

Gambaran Kegelapan Melasma Sesudah Terapi Akupunktur Menggunakan Titik Zusanli dan Taichong

\begin{tabular}{lll}
\hline Kategori & Jumlah & Persentase \\
\hline Nyaris tak terlihat & 2 & $7.7 \%$ \\
Ringan & 6 & $23.1 \%$ \\
Sedang & 13 & $50.0 \%$ \\
Berat & 5 & $19.2 \%$ \\
\hline Total & 26 & $100.0 \%$ \\
\hline \multicolumn{2}{r}{ Dari tabel } & 3 diketahui responden
\end{tabular}
total berjumlah 26 orang, dengan mengkategorikan tingkat kegelapan melasma setelah penusukan titik Zusanli dan Taichong. Kategori nyaris tak terlihat berjumlah 2 orang dengan persentase $7.7 \%$, kategori ringan berjumlah 6 responden dengan persentase $23.1 \%$, kategori sedang berjumlah 13 orang dengan persentase $50 \%$, dan kategori berat berjumlah 5 orang dengan persentase $19.2 \%$

d. Penurunan tingkat kegelapan warna melasma

Tabel 7

Gambaran Penurunan Tingkat Kegelapan Warna Melasma Setelah Terapi Akupunktur Dengan Titik Zusanli Dan Taichong

\begin{tabular}{lll}
\hline $\begin{array}{l}\text { Penurunan } \\
\text { Kegelapan Melasma }\end{array}$ & Frekuensi & Persentase \\
\hline 0 & 20 & $76.9 \%$ \\
1 & 6 & $23.1 \%$ \\
Total & 26 & $100 \%$ \\
\hline
\end{tabular}


Dari tabel 7 dapat diketahui nilai penurunan kegelapan warna melasma sebesar 0 (tidak ada Perubahan ) dan 1 (ada perubahan), artinya bahwa kegelapan melasma yang tidak mengalami penurunan sebanyak 20 responden dengan persentase $76.9 \%$ dan kegelapan melasma yang mengalami penurunan sebanyak 6 responden dengan persentase $23.1 \%$.

Berdasarkan uji normalitas yang didapatkan sebelum perlakuan adalah nilai $\mathrm{P}=0.000$, dan sesudah perlakuan didapatkan nilai $\mathrm{P}=0.002$. Oleh karena nilai Sig (signifikansi) kurang dari 0.05 maka dapat deskripsikan sebagai distribusi tidak normal $(\mathrm{p}<0.05)$. Sehingga untuk pengujiannya menggunakan uji Wilcoxon.

Pada Uji Wilcoxon terhadap tingkat kegelapan melasma sebelum dan sesudah penusukan titik Zusanli dan Taichong didapatkan bahwa nilai signifikansi $\mathrm{p}=0,014<0,05$ maka Ho ditolak yang artinya ada perbedaan tingkat kegelapan warna melasma sebelum dan sesudah penusukan titik Zusanli dan Taichong, dengan kata lain penggunaan titik Zusanli dan Taichong efektif untuk menurunkan tingkat kegelapan warna melasma.

\section{PEMBAHASAN}

Pengertian secara klinis, Melasma adalah hipermelanosis didapat yang umumnya simetris berupa makula yang tidak merata berwarna coklat muda sampai coklat tua, mengenai area yang terpajan sinar ultra violet pada sinar matahari dengan tempat predileksi pada pipi, dahi, daerah atas bibir, hidung, dan dagu. (Soepardiman L, 2007)

Melasma merupakan salah satu masalah kulit yang banyak dijumpai, karena timbulnya melasma menimbulkan gangguan pada kulit wajah sekaligus menyebabkan penurunan kepercayaan diri pada penderitanya. (Bleehen SS 2004).

Kulit yang lebih gelap cenderung memiliki sel pembuat melanin yang lebih besar yang menghasilkan melanosom yang lebih padat, lebih besar sehingga melepas granul pigmen lebih banyak. Biosintesis melanin terjadi didalam melanosom, dibawah pengaruh genetik dan dapat dipengaruhi pula oleh stimulus dari luar seperti sinar matahari. (Kariosentono H. 2002).

Paparan sinar matahari yang banyak di Indonesia yang menimbulkan efek buruk sering tidak diimbangi oleh kesadaran masyarakat dalam melindungi kesehatan kulit, hal ini sering dikaitkan dengan pengetahuan dan jenis pekerjaan dari individu itu sendiri. Tetapi ada beberapa faktor risiko yang dianggap berperan pada patogenesis melasma antara lain: Sinar ultra violet, hormon, obat, genetik, ras, kosmetika dan sisanya idiopatik. (Salim H. 2011)

Pada penelitian ini diharapkan dapat memberikan informasi mengenai efektifitas penggunaan titik Zusanli ( $\mathrm{St}$ 36) dan Taichong ( $\operatorname{Lr} 3$ ) pada kasus melasma.

Berdasarkan umur didapatkan sebanyak 8 responden berusia antara 30 45 tahun dengan persentase $30.8 \%$ dan responden penelitian berusia 45 - 60 tahun sebanyak 18 orang dengan persentase $69 \%$. Sesuai dengan penelitian yang dilakukan oleh Praningrum yang menyebutkan bahwa sebagian besar penderita Melasma berusia antara 41-50 tahun dengan persentase $(39,5 \%)$. Usia subyek penelitian termuda yaitu 17 tahun, sedangkan usia tertua subyek penelitian yaitu 52 tahun.

Hasil analisis bivariat didapatkan kesimpulan bahwa penusukan titik Zusanli 
dan Taichong efektif untuk menurunkan tingkat kegelapan warna melasma. Hal ini sesuai dengan teori Zheng mei-feng pada tahun 2007, yang menjelaskan bahwa melasma berhubungan dengan disfungsi hati, limpa dan ginjal. gangguan emosi dan stagnasi qi hati juga dapat menyebabkan statis darah dan kemudian menyebabkan obstruksi qi meridian di wajah dan mengakibatkan perubahan warna di kulit, diet yang tidak tepat juga dapat merusak limpa dan limpa gagal dalam transportasi dan transformasi sehingga tidak dapat mengatur kelembaban air, qi dan darah sehingga dapat menyebabkan terjadinya melasma.

Pola makan yang salah kesukaan akan makanan pedas atau alkoholisme menyebabkan kerusakan jinye sehingga terjadi defisiensi darah, membuat qi dan darah tidak harmonis dan wajah tidak dapat ternutrisi dengan baik sehingga menyebabkan terjadinya melasma. Selain itu, pola makan yang salah akan mengganggu fungsi lambung dan limpa, mempengarhi fungsi transportasi dan transformasi.

\section{KESIMPULAN DAN SARAN}

Gambaran kegelapan melasma sebelum dilakukan terapi akupunktur adalah kategori tingkat 4 untuk nilai tertinggi, nilai terendah adalah kategori tingkat 2. Gambaran tingkat kegelapan melasma setelah dilakukan terapi akupunktur adalah tingkat 1 untuk nilai terendah, nilai tertinggi adalah tingkat 4 . Terapi akupunktur menggunakan titik Zusanli dan Taichong efektif untuk menurunkan tingkat kegelapan melasma. $(\mathrm{p}=0,014 ; \mathrm{p}<0,05)$.

Pasien Diharapkan mengikuti program terapi sesuai jadwal yang telah ditentukan agar mendapatkan hasil yang maksimal, mentaaati saran dan anjuran yang telah diberikan oleh terapis.

Terapis dapat menerapkan teori dan mendapatkan gambaran pengalaman praktis dalam penelitian tentang penggunaan titik Zusanli (ST 36) dan Taichong (LR 3) terhadap kasus Melasma. mendapatkan gambaran tentang penggunaan titik jauh (Zusanli dan Taichong) dalam penggunaan terhadap kasus melasma selain memakai titik lokal wajah saja. Sebagai satu bahan masukan bagi profesi untuk pengembangan konsep dan kajian yang lebih mendalam tentang penggunaan titik Zusanli (ST 36) dan Taichong (LR 3) untuk penurunan tingkat kegelapan melasma. Untuk penelitian selanjutnya perlu diperluasnya tempat penelitian dan melakukan randomisasi agar hasilnya dapat dimanfaatkan masyarakat luas dan faktor pengganggu yang dapat mempengaruhi hasil penelitian dapat lebih dipertimbangkan.

\section{DAFTAR RUJUKAN}

Bleehen SS, Anstey AV. 2004. Disorder of skin colour : pathogenesis of disorders of melanin pigmentation, melasma. Dalam: Burns $\mathrm{T}$, Breathnach S, Cox N, Griffiths C, editor. Rook's textbook of dermatology. Edisi ke 7. Massachusetts: Blackwell. bag.39. hal.13-14,40.

Brown G.R., Burns T. 2005 Lecture Notes in Dermatology. Jakarta: Erlangga.

Dwi P. 2012. Faktor Resiko Penderita Melasma. Semarang : UNDIP

Febrianti T, Sudharmono A, Rata IGAK, Bernadette I. 2004. Epidemiologi melasma di poliklinik departemen ilmu kesehatan kulit dan kelamin RS. Dr. Cipto mangunkusumo Jakarta 
Kariosentono H. 2002. Kelainan pigmentasi dan penuaan dini serta peran pendidikan kedokteran di bidang ilmu kesehatan kulit dan kelamin. Universitas Sebelas Maret

Rikyanto.2004. Profil kasus melasma pelanggan klinik kosmetik di RSUD kota Yogyakarta.

Salim H. 2011. Pigmentasi kulit

Soepardiman L. 2007. Kelainan pigmen. Dalam: Djuanda A, Hamzah M, Aisah S, editor. Ilmu Penyakit Kulit Dan Kelamin. Edisi ke 5. Jakarta: Balai Penerbit FKUI; hal.289-95.

Zheng Mei-feng. 2007. Acupuncture Cosmetology. China : Shanghai Scientific and Technical Publishers 